\title{
E-BETA THALASSEMIA WITH EXTRAMEDULARY HEMATOPOIESIS: A CASE REPORT
}

Avik Chakraborty ${ }^{1}$, Dulal Chakraborty ${ }^{2}$, Anindya Sundar Trivedi ${ }^{3}$

\section{HOW TO CITE THIS ARTICLE:}

Avik Chakraborty, Dulal Chakraborty, Anindya Sundar Trivedi. "E-Beta Thalassemia with Extramedulary Hematopoiesis: A Case Report". Journal of Evolution of Medical and Dental Sciences 2014; Vol. 3, Issue 33, August 07; Page: 8929-8932, DOI: $10.14260 /$ jemds/2014/3146

ABSTRACT: Extramedullary hematopoiesis (EMH) is a well-recognized process in which the body attempts to maintain erythrogenesis in response to an alteration in the normal production of red blood cells. It is observed in hemoglobinopathies, myeloproliferative disorders, neoplasm's involving the bone marrow and other conditions. Commonly observed areas of EMH include the paraspinal regions of the thorax, liver and spleen, but it has been reported in other locations, including the adrenal gland, bowel, dura mater and breast. Our patient presented with E beta-thalassemia along with hypogonadism who was later diagnosed of having EMH by imaging studies.

KEYWORDS: E-Beta Thalassemia, Extramedulary Hematopoiesis.

INTRODUCTION: Extramedullary hematopoiesis (EMH) is a common compensatory mechanism for chronic anemia found in patients with hemoglobinopathies such as thalassemia, sickle cell anemia, and hereditary spherocytosis. These patients are usually asymptomatic. EMH usually manifests in the thorax as multiple posterior mediastinal or paravertebral masses and masses along the lateral margins of the ribs. ${ }^{1-3}$ Herein, we report a patient with $\mathrm{E}$ beta-thalassemia disease who presented with exertional dyspnea later diagnosed of having EMH by imaging studies along with hypogonadism.

CASE REPORT: A 32years old male patient presented in the OPD with complaints of generalized weakness for last 2 -3months along with dyspnea on exertion for last one month. He also complained of erectile dysfunction and decreased libido for last two years and sparse axillary and pubic hair. He received 30 units of blood for chronic anaemia for last 10 years. There was no history of orthopnea, PND, chest pain or syncopal attack. There was no history of associated fever but he complaints of occasional non-productive cough. No history of any haemoptysis. His bowel and bladder habits are normal.

On examination, patient was emaciated and was pale, icteric and tachypneic. He was tachycardic $(110 / \mathrm{min})$ and normotensive $(110 / 70 \mathrm{~mm} \mathrm{Hg})$. Patient also had testicular atrophy. Systemic examination revealed hepatomegaly and massive splenomegaly. There was grade $4 / 6$ pancystolic murmur in the mitral area along with loud P2 in pulmonary area. Chest auscultation also revealed bilateral reduced breath sounds and chest resonance was impaired on percussion in bilateral mammary and inframammary area.

Investigations revealed patient was anaemic (Hb- 6.6gm/dl), TLC- 4500/mm, ${ }^{3}$ DLC- N22 L74 M02 E00 B02 and platelet count was 2.4 lakhs/cu mm. Peripheral blood smear showed marked anisopoikilocytosis, polychromasia and hypochromia to severe degree. LFT revealed S. bilirubin- 4.6 mg/dl (Direct-2.6, indirect 2.0), ALP- $162 \mathrm{IU} / \mathrm{L}$, AST- 177IU/L, ALT- 110IU/L, Total protein- 7.4 g/dl, A/G ratio- 1.8:1. Ferritin level was $4090 \mathrm{ng} / \mathrm{ml}$. Testosterone level was $157.08 \mathrm{ng} / \mathrm{ml}$ and free testosterone level was $1.14 \mathrm{pg} / \mathrm{ml}$. 


\section{CASE REPORT}

Chest X-ray PA View showed bilateral homogenous opacities ${ }^{\mathrm{Fig} ; 1}$ involving middle zones. CECT

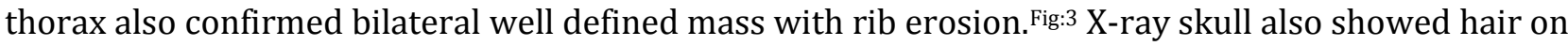
end appearance. ${ }^{\text {Fig:2 }}$ USG whole abdomen showed moderate hepatomegaly with huge splenomegaly, extensive splenic micro calcification, dilated PV and SPV and microlith in right kidney. Echocardiography revealed severe MR with PAH. FNAC study of the lung mass revealed it to be a site of extra medullary erythropoiesis. ${ }^{\text {Fig:4 }}$

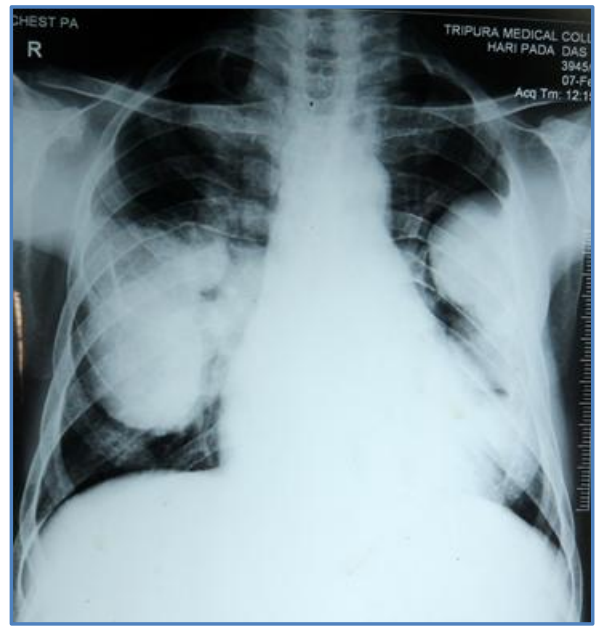

Fig. 1

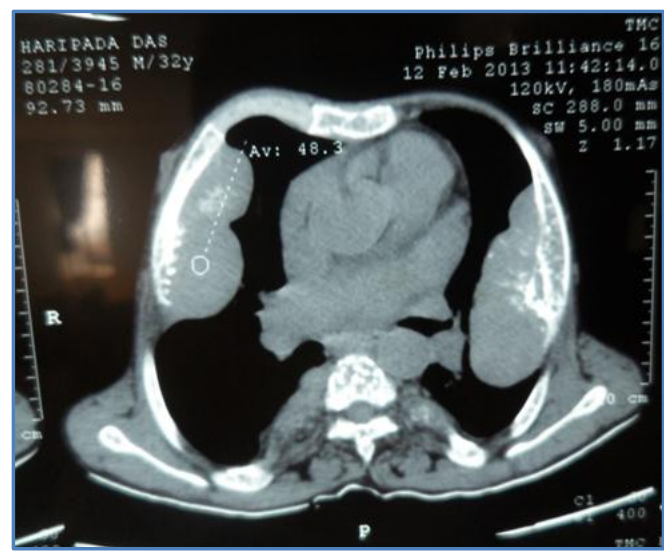

Fig. 3

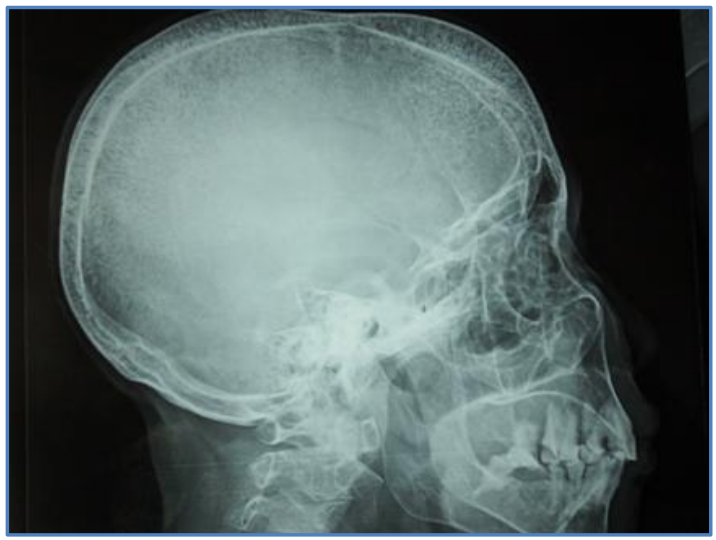

Fig. 2

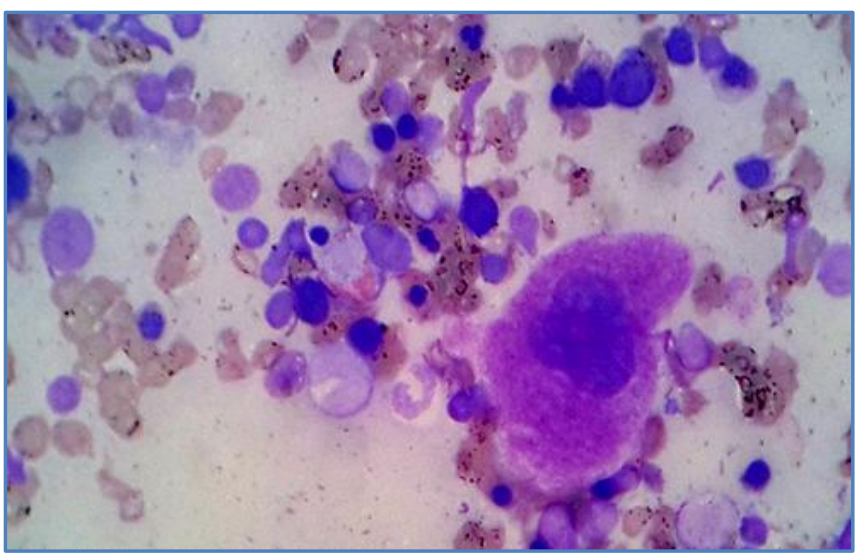

Fig. 4

DISCUSSION: Extramedullary hematopoiesis is seen in a variety of hematologic disorders. It usually develops as a compensatory response in patients with severe haemolytic anaemia such as thalassemia and conditions such as myelofibrosis and myelophthistic anaemia, where there is extensive replacement of normal marrow.

The most common sites of extramedullary hematopoiesis are the liver, spleen and lymph nodes. This condition is rarely manifested as a mass-like lesion within the thorax in patients who have history of frequent blood transfusion and in whom hemoglobin level is kept above 7 
$\mathrm{g} / \mathrm{dL}^{2}$ However, EMH is commonly found in thalassemia-intermedia patients, who usually reach adult life without the need for frequent blood transfusion, because their erythropoiesis is not suppressed. ${ }^{2}$

EMH masses are usually located in the lower paravertebral areas and are usually multiple and bilateral.1-3

Pathologically they may appear as lobulated dark red-purple fleshy paravertebral masses, without destruction of adjacent ribs and vertebrae, which helps distinguish them from other conditions, such as neurogenic tumors. ${ }^{3}$ Other sites of intrathoracic EMH include the anterior mediastinum ${ }^{1}$ and pleura. ${ }^{5}$

The pathogenesis of intrathoracic EMH includes the extrusion of bone-marrow stem cells through the thin cortex of the vertebral bodies and ribs, abetted by negative pres-sure; proliferation of the stem cells, which transform into a nodule of hematopoietic tissue upon demand; and proliferation of the embolized hematopoietic tissues from other areas to the intrathoracic region, such as the spleen. ${ }^{1}$

CT with intravenous contrast enhancement is a useful imaging method for identifying EMH. The typical CT appearance of EMH is smoothly marginated, soft-tissue masses with homogeneous enhancement along the paravertebral regions. 4,6,7 The masses may extend into the epidural space and cause spinal-cord compression. ${ }^{9,10}$ On magnetic resonance imaging, EMH may appear as iso intense paravertebral masses on both T1- and T2-weighted images, with intermediate enhancement after administration of a paramagnetic agent. ${ }^{10}$

Technetium ${ }^{9}$ sulfur colloid radionuclide bone marrow scan may show increased tracer activity in the lung and intrathoracic cav-ity. ${ }^{8}$ Cytological study of the pleural fluid may reveal enlarged mega karyocytes, along with factor-VIII-related antigen immunoreactivity. ${ }^{11}$ Low-dose radiation should be the treatment of choice, because EMH tissues are highly radiosensitive. ${ }^{5}$

Radiation therapy in conjunction with transfusion can inhibit hematopoiesis and decrease the risk of recurrence. ${ }^{12}$ Saxon etal ${ }^{13}$ demonstrated that hydroxyurea can induce regression of EMH and reduce ineffective erythropoiesis in beta-thalassemic patients with bony and spinal complications. Splenectomy may help eliminate the main site of red-blood-cell destruction, as previously reported in patients with hereditary spherocytosis.

\section{REFERENCES:}

1. Chu K. A, Lai R. S, Lee C. H, Lu J. Y, Chang H. C, Chiang H. T. Intrathoracic extramedullary haematopoiesis complicated by massive haemothorax in alpha-thalassaemia. Thorax 1999; 54 (5): 466-468.

2. Chute DJ, Fowler DR. Fatal hemothorax due to rupture of an intrathoracic extramedullary hematopoietic nodule. Am J ForensicMed Pathol 2004; 25 (1): 74-77.

3. Smith PR, Manjoney DL, Teitcher JB, Choi KN, Braverman AS.-Massive hemothorax due to intrathoracic extramedullary hematopoiesis in a patient with thalassemia intermedia. Chest 1988; 94 (3): 658-660

4. Xiros N, Economopoulos T, Papageorgiou E, Mantzios G, Raptis S. Massive hemothorax due to intrathoracic extramedullary hematopoiesis in a patient with hereditary spherocytosis. Ann Hematol 2001; 80 (1): 38-40. 
5. Kupferschmid JP, Shahian DM, Villanueva AG. Massive hemothorax associated with intrathoracic extramedullary hematopoiesis involving the pleura. Chest 1993; 103 (3): 974975.

6. Muthuswamy PP, Shah P, Patel R, Ahuja J, Barker WL. Intrathoracic extramedullary hematopoiesis simulating post-traumatic intrathoracic hemorrhage. Am J Med 1989; 86 (3): 358-360.

7. Tassiopoulos S, Konstantopoulos K, Rombos Y, Aessopos A. Hemothorax due to extramedullary erythropoietic masses. Ann Thorac Surg 2004; 77 (1): 323-324.

8. Bartlett RP, Greipp PR, Tefferi A, Cupps RE, Mullan BP, Trastek VF. Extramedullary hematopoiesis manifesting as a symptomatic pleural effusion. Mayo Clin Proc 1995; 70 (12): 1161-1164.

9. Luyendijk W, Went L, Schaad HDG. Spinal cord compression due to extramedullary hematopoiesis in homozygous thalassemia. Case report. J Neurosurg 1975; 42 (2): 212-216.

10. Chourmouzi D, Pistevou-Gompaki K, Plataniotis G, Skaragas G, Papadopoulos L, Drevelegas A. MRI findings of extramedullary haematopoiesis. Eur Radiol 2001; 11 (9): 1803-1806.

11. Yazdi HM. Cytopathology of extramedullary haematopoiesis in effusions and peritoneal washings: a report of three cases with immunohistochemical study. Diagn Cytopathol 1986; 2 (4): 326-329.

12. Kaufmann T, Coleman M, Giardina P, Nisce LZ. The role of radiation therapy in the management of hematopoietic neurologic complications in thalassemia. Acta Haematol 1991; 85 (3): 156159.

13. Saxon BR, Rees D, Oliveiri NF. Regression of extra medullary haematopoiesis and augmentation of fetal haemoglobin concentration during hydroxyurea therapy in thalassaemia. Br J Haematol 1998; 101 (3): 416-419.

\section{AUTHORS:}

1. Avik Chakraborty

2. Dulal Chakraborty

3. Anindya Sundar Trivedi

\section{PARTICULARS OF CONTRIBUTORS:}

1. Associate Professor, Department of Medicine, Tripura Medical College and Dr. Bram Teaching Hospital, Hapania, Agartala.

2. Assistant Professor, Department of Medicine, Department of Medicine, Tripura Medical College and Dr. Bram Teaching Hospital, Hapania, Agartala.

3. $2^{\text {nd }}$ Year PGT, Department of Medicine, Tripura Medical College and Dr. Bram Teaching Hospital, Hapania, Agartala.

\section{NAME ADDRESS EMAIL ID OF THE CORRESPONDING AUTHOR: \\ Dr. Avik Chakraborty, Department of Medicine, TMC \& Dr. Bram Teaching Hospital, Hapania, Agartala. \\ Email:dravik1975@gmail.com}

Date of Submission: 17/07/2014. Date of Peer Review: 18/07/2014. Date of Acceptance: 31/07/2014. Date of Publishing: 06/08/2014. 